\title{
A comparison of changes in the mucous glands and goblet cells of nasal, sinus, and bronchial mucosa
}

\author{
PATRICIA A. BURTON AND M. F. DIXON \\ From the Department of Pathology, University of Edinburgh
}

\begin{abstract}
A comparison of mucous gland size in the bronchial and nasal mucosa was performed on material from 24 random necropsies. The Reid index and counts of mucous gland acini were used as measures of hypertrophy. In 14 of these cases the relationship between goblet cell hyperplasia in the sinus mucosa and the presence of chronic bronchitis was investigated by comparing the proportion of goblet cells with the corresponding Reid index. No significant correlation was found between nasal and bronchial mucous gland size, and no association was demonstrated between the proportion of goblet cells in the sinus mucosa and the presence of chronic bronchitis as assessed by the Reid index. These findings suggest that a direct association between chronic bronchitis and chronic sinusitis probably does not exist, and that the inclusion of chronic bronchitis in the 'sino-bronchial syndrome' is not valid. We feel that this term should be restricted to the association of chronic sinusitis with bronchiectasis or adult pulmonary mucoviscidosis. If either infection or air pollution were the predominant cause of mucous gland hypertrophy, changes similar to those found in the bronchi would be expected in the nose and sinuses. Since our results show they are not found there, then some other factor, such as cigarette smoking, must be responsible.
\end{abstract}

Pathological criteria for the diagnosis of chronic bronchitis have now been established and are widely accepted. The major criteria are hypertrophy of mucous glands and an increased proportion of goblet cells in the bronchial epithelium. Reid (1960) described a method for quantitating mucous gland hypertrophy by expressing the gland size as a ratio of the mucous gland thickness to the total width of the bronchial mucosa. This measurement is generally referred to as the Reid index, and it may be better correlated to smoking history than to chronic bronchitis. In addition, she utilized the absolute increase in size of the constituent acini of these glands as a measure of hypertrophy, by counting the number of acini filling a standard high-power field.

Diseases of the upper respiratory tract are frequently seen in association with pulmonary disease ; in particular, there is a well-established association between bronchiectasis and chronic sinusitis (Thomson, 1914; Quinn and Meyer, 1929; Hogg and Brock, 1950; Szpunar and Okrasinska, 1962). Furthermore, rhino-sinusitis is often associated with a chronic productive cough similar to that of chronic bronchitis (Hinshaw and Garland, 1963).

The upper nose is lined by a respiratory type of pseudo-stratified, ciliated, columnar epithelium richly supplied with goblet cells, the lamina proe pria containing numerous racemose sero-mucinous glands. The appearances are essentially similar to those in the bronchi though there appears to be. a higher proportion of serous cells in the nasat glands.

The accessory nasal sinuses are lined by a con: tinuation of the nasal mucosa, but here it is muct thinner, with fewer goblet cells. Racemose glands are scarce, being mostly found around the ostio in the maxillary antra.

Long-standing inflammation in the sinuses lead용 to a mucosal reaction similar to that found in the bronchial mucosa; thus mucous gland hyper: trophy and goblet-cell hyperplasia are also features of chronic sinusitis (Eggston and Wolff, 1947).

The uniformity of the microscopic structure and function of the epithelial cells lining the wholes respiratory tract led Cawthorne and Edward? (1966) to postulate that the response of this mene brane to inspired air will be the same whether lines the nasal cavities or the lower bronchi. Theif review of changes in ciliary action and mucus secretion in health and disease substantiated the essential unity of the respiratory responses to airo borne infection and atmospheric pollution.

In view of the physiological continuity of the respiratory mucosa and the close links between 
sinus and pulmonary disease, it was our purpose to determine whether the development of mucousgland hypertrophy and goblet cell hyperplasia in the bronchial mucosa of patients with chronic bronchitis was paralleled by similar changes in the nasal and sinus mucosa irrespective of the presence of overt sinusitis. We preferred to use the Reid index rather than measurements of absolute size by point-counting techniques. The absolute size of mucous glands depends on tissue processing, obliquity of sections, and perhaps body size (Thurlbeck and Angus, 1967). The mucous gland area is dependent on bronchial size and striking differences in gland area are found from site to site in an individual subjeot (Restrepo and Heard, 1963). This means that the Reid index has the advantage that it is a relative measurement and the size of the bronchus is immaterial.

\section{MATERIALS}

The specimens were obtained from 44 randomly selected necropsies performed in the Royal Infirmary, Edinburgh, during 1967. The samples of nasal and sinus mucosa were removed without disfiguring the cadaver by a bilateral sublabial antrostomy. An incision was made high in the upper gingivo-labial fold and the tissues were rasped away from an area of bone over the anterior wall of the maxillary antrum.

A $1-\mathrm{cm}$. square piece of this bone was chiselled away with the attached anterior wall mucosa, giving access to the sinus and to its nasal wall. A similarly sized piece of the thin wall from an area between the ostium and the inferior turbinate with its coverings of antral and nasal mucosae was also removed using a chisel and scalpel. These specimens were fixed in corrosive formol solution for 24 hours, and the mucoperiostium together with the overlying mucosa was then stripped from the supporting bone. This resulted in minimal distortion of the mucosa during fixation and ensured that the entire thickness was present in the section.

Complete transverse blocks were taken from both major bronchi of all cases, about $1 \mathrm{~cm}$. proximal to their divisions, and were fixed in corrosive formol.

Paraffin sections, $7 \mu$ thick, were prepared from these tissues and stained with haematoxylin and eosin.

Of the 44 cases so prepared, autolysis and operative trauma reduced to 24 the number of cases in which both bronchial and nasal measurements could accurately be taken, and in only 14 cases was the superficial mucosa of the anterior antral wall sufficiently intact for a goblet cell count to be made.

\section{METHODS}

The mounted sections were projected on to a vertical white board using a Leitz micro-projector system, and

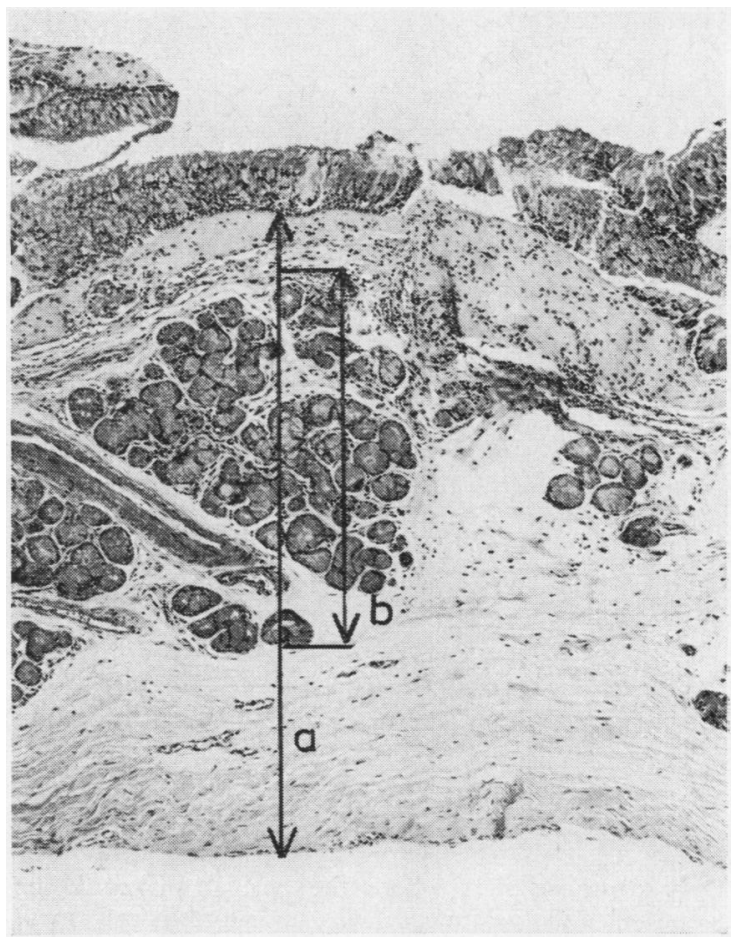

FIG. 1. Mucosa from lateral wall of nose. $(\times 60) \quad a=$. width of the mucosa from the inner aspect of the epithelial basement membrane to the intact lower border of mucoperiosteum. $b=$ maximum width of the mucous gland. $b / a$ was compared to the corresponding Reid index.

the magnified image was measured directly with a finely calibrated transparent ruler.

In the sections of the major bronchi the maximal gland thickness was measured on a line at right angles to the plane of the cartilage, and the total mucosal thickness (inner aspect of perichondrium to inner aspect of basement membrane) was measured on exactly the same line. At least four glands were measured in each bronchus, and the ratio of glandto-wall thickness was calculated for each gland. The mean of these ratios gave the Reid index of each bronchus.

The recommendations of Thurlbeck and Angus (1967) were followed in that glands at the edges of the cartilage were not measured, and the Reid index was calculated for both major bronchi, as they found that the mean index of these two sites correlated closely $(r=0.96)$ with the mean of six sites from the bronchial tree.

The sections of nasal mucosa were measured in a similar manner, the thickness being taken from the lower aspect of the muco-periosteum to the inner aspect of the epithelial basement membrane (Fig. 1). 


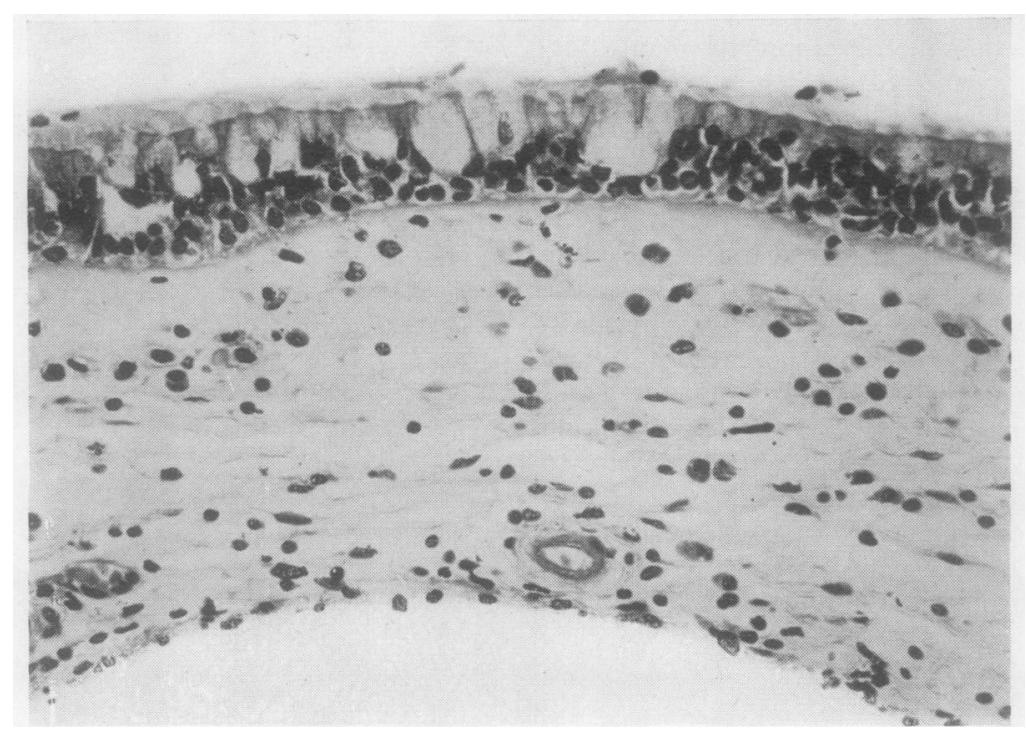

FIG. 2. Mucosa from maxillary antrum, showing goblet cells. $(\times 325$.

Only at those sites where the periosteum could be identified and the mucosa was undistorted were measurements taken, from two to four readings being taken from each specimen.

As all these results were ratios, changes in magnification between sections were of no consequence.

The acinar counts were made by direct microscopy, the number of acini, complete or incomplete, in a high-power field being recorded.

A $4-\mathrm{mm}$. objective and $\times 6$ eye-pieces were used. Counts were made in glands where the high-power field was completely filled with regular, defined acini without mucous pools. Fields within at least four glands in each bronchus, and in a minimum of four nasal mucous glands, were counted.

The goblet-cell counts of sinus mucosa were made on intact strips of maxillary mucosa (Fig. 2) where all cells were identifiable and undistorted. The number of goblet cells in 100 epithelial cells was ascertained for each strip. Usually two to three strips suitable for measurement were found.

\section{RESULTS}

Table I shows the mean Reid index for each case, arranged in order of magnitude, and the corresponding value of the gland: wall ratio in the nasal mucosa. Although the ratios obtained from the nasal mucosa and the Reid indices were of similar magnitude, on comparison there was no significant correlation between the mean Reid index of the bronchi and the corresponding gland: wall ratio $(r=0.0599, \mathrm{P}>0 \cdot 1$.
T A B L E I

THE REID INDEX AND CORRESPONDING GLAND: WALL RATIOS IN NASAL MUCOSA

\begin{tabular}{|c|c|c|c|c|}
\hline \multirow[b]{2}{*}{ Case No. } & \multicolumn{2}{|c|}{ Bronchial Mucosa } & \multicolumn{2}{|c|}{ Nasal Mucosa } \\
\hline & $\begin{array}{l}\text { Mean } \\
\text { Reid } \\
\text { Index }\end{array}$ & $\begin{array}{c}\text { Standard } \\
\text { Error of } \\
\text { Mean }\end{array}$ & $\begin{array}{c}\text { Mean } \\
\text { Gland: } \\
\text { Wa'l Ratio }\end{array}$ & $\begin{array}{c}\text { Standard } \\
\text { Error of } \\
\text { Mean }\end{array}$ \\
\hline $\begin{array}{r}1 \\
2 \\
3 \\
4 \\
5 \\
6 \\
7 \\
8 \\
9 \\
10 \\
11 \\
12 \\
13 \\
14 \\
15 \\
16 \\
17 \\
18 \\
19 \\
20 \\
21 \\
22 \\
23 \\
24\end{array}$ & $\begin{array}{l}0 \cdot 31 \\
0 \cdot 325 \\
0 \cdot 335 \\
0 \cdot 34 \\
0 \cdot 36 \\
0 \cdot 36 \\
0 \cdot 38 \\
0 \cdot 395 \\
0 \cdot 40 \\
0 \cdot 40 \\
0 \cdot 405 \\
0 \cdot 44 \\
0 \cdot 44 \\
0 \cdot 45 \\
0 \cdot 45 \\
0 \cdot 455 \\
0 \cdot 475 \\
0 \cdot 475 \\
0 \cdot 525 \\
0 \cdot 545 \\
0 \cdot 555 \\
0 \cdot 57 \\
0 \cdot 58 \\
0 \cdot 585\end{array}$ & $\begin{array}{l}0.04 \\
0.015 \\
0.015 \\
0.03 \\
0.02 \\
0.03 \\
0.01 \\
0.045 \\
0 \cdot 11 \\
0.03 \\
0.015 \\
0.01 \\
0.02 \\
0.01 \\
0.01 \\
0.025 \\
0.045 \\
0.045 \\
0.115 \\
0.015 \\
0.045 \\
0.03 \\
0.01 \\
0.025\end{array}$ & $\begin{array}{l}0.46 \\
0.59 \\
0.38 \\
0.55 \\
0.55 \\
0.33 \\
0.49 \\
0.49 \\
0.39 \\
0.50 \\
0.48 \\
0.50 \\
0.47 \\
0.55 \\
0.42 \\
0.61 \\
0.58 \\
0.50 \\
0.54 \\
0.60 \\
0.40 \\
0.41 \\
0.49 \\
0.48\end{array}$ & $\begin{array}{l}0.088 \\
0.14 \\
0.096 \\
0.14 \\
0.16 \\
0.097 \\
0.14 \\
0.057 \\
0.063 \\
0.13 \\
0.075 \\
0.13 \\
0.025 \\
0.22 \\
0.053 \\
0.067 \\
0.01 \\
0.045 \\
0.076 \\
0.088 \\
0.089 \\
0.035 \\
0.057 \\
0.102\end{array}$ \\
\hline
\end{tabular}

The mean Reid index for each case was calculated by taking the mean of the indices of the major bronchi, which, in turn, were the means of at least four individual gland: wall ratios measuredo at the same site. In common with the findings of previous studies on the Reid index, there was a highly significant correlation between the mean Reid index of each major bronchus $(r=0.6087$, 
$\mathbf{P}>0.001$ ). Nevertheless, in some sections a wide range of individual gland:wall ratios was observed, and it was apparent that a single measurement of the Reid index could not be taken as representative of the section.

Table II shows the mean acinar count obtained from the bronchial mucous glands for each case,

T A B LE I I

MEAN ACINAR COUNTS OBTAINED FROM BRONCHIAL AND NASAL MUCOUS GLANDS

\begin{tabular}{|c|c|c|c|c|}
\hline \multirow[b]{2}{*}{ Case No. } & \multicolumn{2}{|c|}{ Bronchial Mucous Glands } & \multicolumn{2}{|c|}{ Nasal Mucous Glands } \\
\hline & $\begin{array}{l}\text { Mean } \\
\text { Acinar } \\
\text { Count }\end{array}$ & $\begin{array}{l}\text { Standard } \\
\text { Error of } \\
\text { Mean }\end{array}$ & $\begin{array}{l}\text { Mean } \\
\text { Acinar } \\
\text { Count }\end{array}$ & $\begin{array}{c}\text { Standard } \\
\text { Error of } \\
\text { Mean }\end{array}$ \\
\hline $\begin{array}{r}1 \\
2 \\
3 \\
4 \\
5 \\
6 \\
7 \\
8 \\
9 \\
10 \\
11 \\
12 \\
13 \\
14 \\
15 \\
16 \\
17 \\
18 \\
19 \\
20 \\
21 \\
22 \\
23 \\
24\end{array}$ & $\begin{array}{l}17 \cdot 0 \\
15.0 \\
23.5 \\
24 \cdot 0 \\
20.5 \\
12.5 \\
21.5 \\
18 \cdot 0 \\
17.0 \\
14.0 \\
12.0 \\
23.0 \\
18.0 \\
17.5 \\
15.0 \\
19.5 \\
2.1 .5 \\
20.5 \\
14.5 \\
14.5 \\
21.0 \\
19.0 \\
19.5 \\
15.5\end{array}$ & $\begin{array}{l}1 \cdot 9 \\
1 \cdot 3 \\
4 \cdot 15 \\
2 \cdot 8 \\
4 \cdot 05 \\
2 \cdot 15 \\
4 \cdot 0 \\
2 \cdot 05 \\
2 \cdot 4 \\
2 \cdot 0 \\
1 \cdot 3 \\
1 \cdot 8 \\
3 \cdot 25 \\
2 \cdot 25 \\
2 \cdot 80 \\
2 \cdot 65 \\
3.40 \\
2.90 \\
1 \cdot 15 \\
2 \cdot 25 \\
2.90 \\
2 \cdot 25 \\
0.90 \\
2 \cdot 55\end{array}$ & $\begin{array}{l}30 \\
22 \\
27 \\
23 \\
20 \\
27 \\
21 \\
22 \\
19 \\
28 \\
24 \\
22 \\
20 \\
24 \\
19 \\
24 \\
22 \\
23 \\
21 \\
18 \\
30 \\
31 \\
28 \\
21\end{array}$ & $\begin{array}{l}4 \cdot 0 \\
1 \cdot 8 \\
4 \cdot 42 \\
4 \cdot 4 \\
2 \cdot 3 \\
4 \cdot 6 \\
3 \cdot 6 \\
2 \cdot 3 \\
2 \cdot 5 \\
5 \cdot 3 \\
2 \cdot 3 \\
2 \cdot 4 \\
2 \cdot 7 \\
2 \cdot 4 \\
2 \cdot 6 \\
2 \cdot 3 \\
4 \cdot 3 \\
4 \cdot 1 \\
1 \cdot 5 \\
1 \cdot 3 \\
5 \cdot 1 \\
4 \cdot 0 \\
3 \cdot 5 \\
2 \cdot 6\end{array}$ \\
\hline
\end{tabular}

and the corresponding values obtained from the nasal glands. The mean bronchial acinar count is based on at least four counts from each bronchus, whilst the nasal count is the mean of a minimum of four, and a maximum of eight counts, performed on two samples of nasal mucosa. Comparison of the mean acinar counts of bronchial and nasal mucous glands showed no significant correlation $(r=0.0955, P>0 \cdot 1)$. There was, however, a highly significant correlation between acinar counts from each bronchus in the same individual $(\mathrm{r}=0.6906, \mathrm{P}>0.001)$.

Table III shows the mean percentage of goblet cells present in the sinus epithelium in the 14 cases where counts were possible, and the corresponding mean Reid index. No significant correlation was found between these values $(r=0.0961$, $\mathbf{P}>(0 \cdot 1)$.

Direct comparison between the goblet cell content of nasal and bronchial epithelium was not possible, as in some of these 14 cases epithelial destruction in the bronchi, resulting from ulceration and post-mortem autolysis, did not allow a satisfactory number of counts to be performed.
T A B L E I I I

MEAN PER CENTAGE OF GOBLET CELLS IN SINUS MUCOSA AND CORRESPONDING VALUES OF REID INDEX

\begin{tabular}{|c|c|c|c|}
\hline $\begin{array}{l}\text { Case } \\
\text { No. }\end{array}$ & $\begin{array}{l}\text { Mean Percentage } \\
\text { of Goblet Cells }\end{array}$ & $\begin{array}{c}\text { Standard Error } \\
\text { of Mean }\end{array}$ & $\begin{array}{l}\text { Mean Reid } \\
\text { Index }\end{array}$ \\
\hline $\begin{array}{r}1 \\
2 \\
3 \\
4 \\
6 \\
7 \\
11 \\
12 \\
14 \\
17 \\
18 \\
20 \\
21 \\
24\end{array}$ & $\begin{array}{l}50 \cdot 0 \\
43 \cdot 5 \\
40 \cdot 0 \\
36 \cdot 5 \\
44 \cdot 5 \\
35 \cdot 5 \\
52 \cdot 5 \\
42 \cdot 0 \\
43 \cdot 5 \\
45 \cdot 5 \\
29 \cdot 0 \\
35 \cdot 0 \\
38 \cdot 0 \\
62 \cdot 5\end{array}$ & $\begin{array}{l}2.0 \\
1.5 \\
3.0 \\
2.5 \\
1.5 \\
4.5 \\
6.5 \\
3.0 \\
0.5 \\
0.5 \\
3.0 \\
5.0 \\
2.5 \\
1.5\end{array}$ & $\begin{array}{l}0.310 \\
0.325 \\
0.335 \\
0.340 \\
0.360 \\
0.380 \\
0.405 \\
0.440 \\
0.450 \\
0.475 \\
0.475 \\
0.545 \\
0.555 \\
0.585\end{array}$ \\
\hline
\end{tabular}

\section{DISCUSSION}

In view of the close histological similarity between nasal, sinus, and bronchial mucosa, and their role as a single physiological unit, we might expect that the increases in mucous gland size and goblet cell count found in chronic bronchitis (Reid, 1954) are paralleled by corresponding changes in the nasal and sinus mucosa. In the first part of this study we have attempted to correlate the size of mucous glands in the bronchi with those in the nasal mucosa, using the Reid index as a measure of hypertrophy.

We hoped that the use of random necropsy material from an essentially urban population with a high incidence of chronic bronchitis would let us observe a wide range of mucous gland sizes. The range of gland: wall ratios obtained from the major bronchi indicated that, as anticipated, the group included a significant proportion in which the degree of glandular hypertrophy was strongly suggestive of chronic bronchitis. Reid (1960) reported 0.36 as the upper limit of the index in her normal group, and Thurlbeck, Angus, and Paré (1963) regarded gland wall ratios above 0.45 as being examples of chronic bronchitis.

A retrospective analysis of the clinical notes revealed that, of the 24 cases studied, 14 were non-bronchitics, and in 10 the history of excessive sputum production was suggestive of chronic bronchitis. Using the level of 0.45 as the upper limit of normal for the Reid index, two of the chronic bronchitics $(20 \%)$ had values below this limit, whilst three of the non-bronchitic group (21\%) had values above 0.45 . The finding of an overlap between these groups is in keeping with the results of Thurlbeck et al. (1963) and Thurlbeck and Angus (1964), who concluded that as the distribution curve of the Reid index in a random population was of the 'normal' type, a 
degree of overlap was inevitable. The distribution of bronchitics in our series, however, does reaffirm the general usefulness of the Reid index as a measure of chronic bronchitis.

In the second part of the study a further pathological feature of chronic bronchitis, namely, the increase in size of mucous acini, was used as a measure of hypertrophy.

Glynn and Michaels (1960) showed that the changes in chronic bronchitis consisted of an increase both in the number of mucous relative to serous glands and in the size of the mucous acini due to swelling of their component cells. They considered that this mucous change in the deep glands is the most important pathological feature of chronic bronchitis. These factors, in combination, should bring about a reduction in the number of acini per unit area, and Reid (1960) recorded significantly lower counts in bronchitics than in normal controls.

In contrast to Reid's findings, Thurlbeck et al. (1963) could not demonstrate any significant difference between the acinar counts obtained from a group of bronchitics and from a normal group. It is obvious that if a diminished acinar count is a valid measure of mucous gland hypertrophy then it should be well correlated with the Reid index. Field, Davey, Reid, and Roe (1966) examined the relationship of the acinar count to the Reid index in the bronchi from 644 necropsies and found them to be only slightly related ( $\mathrm{r}=$ approx. $0 \cdot 4$ ) but that this low degree of association was significant. However, using the results of the present study, no significant correlation was demonstrated between the mean acinar count and the Reid index $(r=0.0601$, $\mathbf{P}>0 \cdot 1)$. A similar lack of correlation was found using the results of Thurlbeck et al. (1963) $(r=0.0672, \quad P>0 \cdot 1)$. We therefore suggest that acinar counts are of doubtful value in assessing mucous gland hypertrophy.

Goblet cell hyperplasia was described by Reid (1954) as an early change in chronic bronchitis, and Glynn and Michaels (1960) reported that many patients in their series showed an increase in surface goblet cells. In addition they demonstrated a positive association between goblet cell hyperplasia and Haemophilus influenzae infection. This emphasized the earlier finding of Brumfitt, Willoughby, and Bromley (1957) that there was a preponderance of $\boldsymbol{H}$. influenzae over other organisms when swabs were taken directly from the bronchi in cases of chronic bronchitis. Rough strains of $\boldsymbol{H}$. influenzae, however, are found in a variable proportion of normal throats. Nevertheless, they are potential pathogens and are asso- ciated with sinusitis when the respiratory tract is $\stackrel{\vec{\Rightarrow}}{\vec{*}}$ less resistant to bacterial invasion (Cruickshank, $\stackrel{\oplus}{+}$ 1968). In view of the established relationship be-? tween upper and lower respiratory tract infections $\frac{\bar{\sigma}}{\bar{D}}$ (Graham, 1931 ; McLaurin, 1943, and Davison, $\frac{\sqrt{\sigma}}{\Phi}$ 1967), we thought there might be some degree of $\propto$ goblet cell hyperplasia in the sinus mucosa of $\%$ individuals with chronic bronchitis even in the $\vec{\circ}$ absence of overt chronic sinusitis. To investigate this the mean percentage of goblet cells present in $\vec{\omega}$ the epithelium of both maxillary sinuses was compared with the corresponding Reid index in $14 \overrightarrow{\vec{x}}$ cases but no significant correlation was found. i

On the basis of the Reid index, the acinar count, $\dot{\sim}$ and the percentage of goblet cells in the epithe- $\vec{\infty}$ lium, our results show that the mucous gland ${ }^{\infty}$ hypertrophy and goblet cell hyperplasia of chronic오 bronchitis are not associated with similar changes in the nasal and sinus mucosa.

Some evidence, contrary to these findings, sug- $\frac{\partial}{2}$ gesting that changes in the sinus mucosa are linked to those found in chronic bronchitis, is provided $\vec{\varnothing}$ by Greenberg and Ainsworth (1966) in their studye of the 'sino-bronchial syndrome'. They examined specimens of sinus mucosa removed at operations for the relief of chronic sinusitis, and found signi- $\frac{\partial}{\partial}$ ficantly increased gland hypertrophy, goblet cell@ numbers, epithelial metaplasia, and thickness of basement membrane in those patients giving a clinical history of chest disease. Unfortunately, this group of 12 cases contained a variety of pulmonary diseases including bronchiectasis, and only one of their four cases of chronic bronchitis was uncomplicated by further pulmonary patho- $\overrightarrow{0}$ logy.

The absence of nasal mucous gland hypertrophy: and goblet cell hyperplasia with unequivocal 3 . chronic bronchitis indicates that any exaggeration of these features in chronic sinusitis is not related 3 to co-existent chronic bronchitis. In our smallo series of 10 cases, there was no direct relationship between chronic sinusitis and chronic bronchitis.

The frequent description of this association probably results from the simultaneous occurrenceo of two common diseases and the inadequate dis- $N$ tinction made between chronic bronchitis andN other chronic pulmonary diseases. There is no doubt, however, that bronchiectasis and adulk pulmonary mucoviscidosis (Shwachman and? Leubner, 1955; Peterson, 1959) are frequentlyọ associated with chronic sinusitis, and we suggest that the term 'sino-bronchial syndrome' should berestricted to these conditions.

These findings also have implications regarding the aetiology of the pathological features of chronic bronchitis. It is widely accepted that long 
standing irritation of the bronchial mucosa is the fundamental aetiological process, and that infection, air pollution, and smoking constitute the most important sources of chronic irritation. The physiological unity of the respiratory mucosa and its widespread involvement by acute bacterial infections have already been emphasized. In view of this it is difficult to appreciate how the nasal and sinus mucosae are not involved in a generalized reaction if infection is the predominant cause of mucous gland and goblet cell changes. A similar argument applies to atmospheric pollution in that the nasal mucosa is subjected to greater irritation by dust particles and fumes than is the bronchial mucosa (Frank, 1964), and alterations in the glands of both nose and bronchi would be expected.

In smoking, however, inhalation and exhalation of the irritant is largely through the mouth, thus sparing the nasal and sinus mucosae. The role of smoking in producing mucous gland hypertrophy has been investigated by Thurlbeck et al. (1963), who examined bronchi from necropsies and grouped their cases according to smoking habits. They found that the Reid index was significantly higher in heavy smokers than in non-smokers. Similarly, Field et al. (1966) found that mucous gland hypertrophy was more common in male cigarette smokers, ex-cigarette smokers, and pipesmokers than in non-smokers, regardless of the place of residence. Megahed, Senna, Eissa, Saleh, and Eissa (1967) studied the smoking habits of 50 proven cases of chronic bronchitis and compared these with the histological findings in bronchial biopsies. They reported a higher incidence of mucous gland hypertrophy in smokers than in non-smokers, a significantly higher accumulated lifetime tobacco consumption in patients exhibiting mucous gland hypertrophy than in those without hypertrophy, and a significant correlation between the degree of mucous gland hypertrophy and the intensity of smoking. In addition, they found no difference in the comparative frequency of occurrence of bronchial mucous gland hypertrophy in subjects with and without demonstrable infection, as shown by the presence of potential pathogens in a bronchial lavage. They concluded that tobacco smoking was the most important underlying cause of bronchial mucous gland hypertrophy.

Despite their close anatomical and physiological similarities there is no correlation between mucous gland size in the bronchial and nasal mucosa, and between the goblet cell content of sinus epithelium and the presence of chronic bronchitis as assessed by the Reid index. As infections and air pollution exert their irritant effects throughout the respiratory tract, we felt that the absence of parallel changes in the nasal mucosa in patients with bronchial gland hypertrophy suggested an aetiological factor acting predominantly on the lower respiratory tract. This could be cigarette smoking, though we were unable to obtain adequate details of our patients' smoking habits, and so could not confirm this.

We are grateful to Professor G. L. Montgomery for criticism of this paper and to Dr. D. G. Woodfield for statistical advice.

\section{REFERENCES}

Brumfitt, W., Willoughby, M. L. N., and Bromley, L. L. (1957). An evaluation of sputum examination in chronic bronchitis. Lancet, 2,1306 .

Cawthorne, T., and Edwards, W. (1966). The respiratory system in health and disease. J. Laryng., 80, 359.

Cruickshank, R. (1968). Medical Microbiology, 11 th ed. (revised), p. 214. Livingstone, Edinburgh.

Davison, F. W. (1967). Chronic sinus and broncho-pulmonary diseases-the relationship. Minn. Med., 50, 855 .

Eggston, A. A., and Wolf, D. (1947). Histopathology of the Ear, Nose and Throat. Williams and Wilkins, Baltimore.

Field, W. E. H., Davey, E. N., Reid, L., and Roe, F. J. C. (1966). Bronchial mucus gland hypertrophy: Its relation to symptoms and environment. Brit. J. Dis. Chest, 60,66 .

Frank, N. R. (1964). Studies on the effects of acute exposure to sulphur dioxide in human subjects. Proc. roy. Soc. Med., 57, 1029.

Glynn, A. A., and Michaels, L. (1960). Bronchial biopsy in chronic bronchitis and asthma. Thorax, 15, 142.

Graham, E. A. (1931). Reaction of bronchial fistulae to acute infections of the upper respiratory tract. Amer. J. Surg., 14, 382.

Greenberg, S. D., and Ainsworth, J. Z. (1966). Comparative morphology of chronic bronchitis and chronic sinusitis, with dis-
cussion of 'sinobronchial' syndrome. Sth. med.J. (Bgham, Ala), $59,64$.

Hinshaw, H. C., and Garland, L. H. (1963). Diseases of the Chest, 2nd ed., p. 192. Saunders, Philadelphia.

Hogg, J. C., and Brock, R. C. (1950). Discussion on the role of sinusitis in bronchiectasis. Proc. roy. Soc. Med., 43, 1089.

McLaurin, J. G. (1943). Interrelationship of upper and lower respiratory infections, emphasizing the routes of infection. Ann. Otol. (St. Louis), 52, 589.

Megahed, G. E., Senna. G. A., Eissa, M. H., Saleh, S. Z., and Eissa, H. A. (1967). Smoking versus infection as the aetiology of mucous gland hypertrophy in chronic bronchitis. Thorax, 22, 271.

Peterson, E. M. (1959). Consideration of cystic fibrosis in adults, with a study of sweat electrolyte values. J. Amer. med. Ass., 171, 1 .

Quinn, L. H., and Meyer, O. O. (1929). The relationship of sinusitis and bronchiectasis. Arch. Otolaryng., 10, 152.

Reid, L. (1954). Pathology of chronic bronchitis. Lancet, 1, 275. (1960). Measurements of the bronchial mucous gland layer: a diagnostic yardstick in chronic bronchitis. Thorax, 15, 132 .

Restrepo, G., and Heard, B. E. (1963). Mucous gland enlargement in chronic bronchitis: extent of enlargement in the tracheo-bronchial tree. Thorax, 18, 334 . Shwachman, H., and Leubner, H. (1955). Mucoviscidosis. Adv.
Pediat., 7, 249 .

Szpunar, J., and Okrasinska, B. (1962). Sinusitis in children with bronchiectasis: the influence of allergy on its development. Arch. Otolaryng., 76, 352.

Thomson, Sir St. Clair (1914). Some of the symptoms and complications of sinusitis. Practitioner, 92, 745.

Thurlbeck, W. M., and Angus, G. E. (1964). A distribution curve for chronic bronchitis. Thorax, 19, 436. (1967). The variation of Reid index measurements within the major bronchial tree. Amer. Rev. resp. Dis., 95, 551 . and Paré, J. A. P. (1963). Mucous gland hypertrophy in chronic bronchitis, and its occurrence in smokers. Brit. J. Dis. Chest, 57, 73 . 